\title{
The PGI-KLF4 pathway regulates self-renewal of glioma stem cells residing in the mesenchymal niches in human gliomas
}

\author{
X. Y. ZHU $U^{1, \ddagger}$, L. WANG ${ }^{2, \star}$, S. H. LUAN ${ }^{3}$, H. S. ZHANG ${ }^{3}$, W. T. HUANG ${ }^{4, *}$, N. H. WANG ${ }^{5,6 *}$
}

${ }^{1}$ Department of traditional Chinese medicine, Shanghai Cancer Hospital, Fudan University, Shanghai, P R China; ${ }^{2}$ Department of blood transfusion, Shanghai RenJi Hospital, Shanghai JiaoTong University, Shanghai, P R China; ${ }^{3}$ Department of Neurosurgery, HuaShan Hospital, Fudan University, Shanghai, PR.China; ${ }^{4}$ Department of Pathology, Shanghai Sixth People's Hospital, Shanghai JiaoTong University, Shanghai, P R China; ${ }^{5}$ Department of Rehabilitation Medicine, Huashan Hospital, Fudan University, Shanghai 200040, China; ${ }^{6}$ Department of Sports Medicine and Rehabilitation, Medical College of Fudan University, Shanghai 200032, China; ${ }^{7}$ Department of Rehabilitation Medicine, The Yonghe Branch of Huashan Hospital, Fudan University, Shanghai Zhabei District 200436, China; ${ }^{8}$ State Key Laboratory of Medical Neurobiology, Fudan University, Shanghai 200032, China

*Correspondence: huangwt1786@163.com,wnh2005@126.com

${ }^{*}$ Contributed equally to this work.

Received September 22, 2013 / Accepted November 18, 2013

\begin{abstract}
Gliomas display cellular hierarchies with self-renewing tumorigenic glioma stem cells (GSCs) at the apex. The GSC niches function as a regulator of GSC maintenance, however, the exact components of GSC niches that mediate this process are still far from fully defined. Here, we showed that glioma cells with aberrant mesenchymal phenotypes constitute a mesenchymal niche for GSCs. Using patient-derived specimens, we demonstrated that the paracrine PGI signaling, initiated by mesenchymal glioma cells, induces the self-renewal and tumorigenic potentials of GSCs through induction of KLF4. Treatment of intracranial orthotopic xenografts with shPGI or shKLF4 leads to less lethal potency. Our data therefore suggest that blockade of the PGI-KLF4 pathway may provide a therapeutic strategy against GSC niches.
\end{abstract}

Key words: gliomas, mesenchymal niches, PGI, KLF4, self-renewal

Glioma is a particularly devastating and lethal form of tumor derived from glia or their precursors within the central nervous system. The identification of distinct glioma subtypes based on gene expression profiling has increased our understanding of the molecular basis of differences in patient survival rate. For example, gene expression studies have established that overexpression of a 'mesenchymal' gene expression signature (MGES) and loss of a proneural signature (PNGES) co-segregate the poor prognosis group of glioma patients $[1,2]$. Indeed, a mesenchymal phenotype is the hallmark of tumor aggressiveness in malignant gliomas [3]. However, little is known about the key molecular alterations that are responsible for driving glioma progression in mesenchymal subgroups.

A key feature of malignant gliomas is the cellular heterogeneity of the bulk tumor mass. There is growing evidence that an individual cellular subpopulation, known as glioma stem cells (GSCs), might possess self-renewing, multipotent, and tumor-initiating capabilities [4-6]. Recently, compelling evidence has related mesenchymal differentiation to the emergence of cancer stem cell (CSC)-like phenotype [7-9]. Similar phenomena have also been observed in malignant gliomas. For example, a shift to a mesenchymal phenotype is frequently observed in recurrent gliomas from the same patient [1]. Meanwhile, the percentage of GSCs was significantly higher in recurrent gliomas than that in autologous primary tissues [10]. Then, a question arises whether a particular process of mesenchymal metaplasia will be sufficient for remolding all the cellular appearances of CSCs. Mesenchymal differentiation is a reversible process that can be induced or reversed by various stimuli in tumor microenvironment [11-13], whereas the current CSC model presumes an irreversible differentiation in tumor tissues $[14,15]$. We proposed that mesenchymal differentiation-induced CSC generation may be rather a sideeffect than a true effect. This opinion seems to be supported by a recent report showing that no changes in CSC marker 
expression have been detected after mesenchymal induction in $K$-ras-dependent pancreatic cancer cells [16].

Instructive cues to maintain GSCs are generated by both intrinsic networks and the niche microenvironment. Intrinsic regulation of GSCs occurs through key proliferative and survival pathways such as c-Myc, Oct4, Olig2, and Bmi1 [17]. Extrinsically, several models have been employed to interrogate the nature of communication between GSCs and their niches $[18,19]$. Apart from the stromal cells (inflammatory cells, endothelial cells, and glial cells) which compose the GSCs niche, differentiated glioma cells defining the tumor mass should also be considered within its immediate tumor microenvironment. We hypothesized that within malignant gliomas undergoing mesenchymal transition, GSCs have gained an ability to adjust their self-renewal ability to given environmental influences, leading to the aberrant expansion of GSCs pool. Here, we focus on a better understanding of the regulatory mechanism of mesenchymal glioma cells on the stemness of GSCs, which may help to identify the potential therapeutic targets.

\section{Materials and methods}

Tumor samples and cell lines. All human glioma specimens were collected from Huashan Hospital. The clinical protocol was approved by Huashan Institutional Review Board (HIRB) with informed consent. Fresh glioma tissues obtained from operating room were processed within $30 \mathrm{~min}$ after surgical resection. Briefly, minced pieces of human glioma samples were digested with $200 \mathrm{U} / \mathrm{ml}$ collagenase I (Sigma) and $500 \mathrm{U} / \mathrm{ml}$ DNAse I (Sigma) in PBS for $2 \mathrm{~h}$ at $37^{\circ} \mathrm{C}$. The singlecell suspension was filtered through a $70 \mathrm{~mm}$ cell strainer $(\mathrm{BD}$ Falcon) and washed with PBS. Finally, cells were resuspended and subsequently cultured in DMEM with 10\% FBS (for primary cultures) or in Neurobasal medium (Invitrogen) (for oncospheres).

Oncosphere initiation assays. To evaluate GSC self-renewal, oncosphere initiation assays were performed in the single-cell suspensions. Equal number of cells was seeded at low cell density ( 4 cells/ $\mu$ l) in wells of a 96 -well plate. Number of spheres was quantified after 14 days. Tumor spheres were then disaggregated and reseeded to evaluate self-renewal by formation of quaternary oncospheres.

Quantitative real-time PCR. qPCR was performed using Taqman probes from Applied Biosystems, according to the manufacturer's recommendations. Reactions were carried out in an ABI 7000 sequence detector (Perkin Elmer) and results were expressed as fold change calculated by the $\Delta \Delta \mathrm{Ct}$ method relative to the control sample or to the first sample quantified. GAPDH was used as internal normalization controls.

Luciferase reporter assays. Cells in 24-well plates were transiently transfected with different KLF4 promoter reporter constructs and pRLTK Renilla luciferase plasmid (Promega) using Fugene 6 (Roche). Cell extracts were prepared $48 \mathrm{~h}$ after transfection, and luciferase activity was measured using the Dual-Luciferase Reporter Assay System (Promega).
Immunocytochemistry and immunohistochemistry. Using antibodies against CD133 (miltenyi), Fibronectin (Chemicon), ki-67 (Sigma), FSTL1 (Abcam) fibronectin (Santa Cruz), YKL40 (Quidel), gp78 (Santa Cruz), immunofluorescence microscopy analysis of oncospheres, primary glioma cells and sections of freshly frozen glioma samples was performed as described [20]. Immunohistochemistry of glioma sections was performed as described previously using the antibody against KLF4 (Chemicon) [20].

Immunoblotting. Total protein was extracted from cells using RIPA lysis buffer (Santa Cruz). Protein extract ( $50 \mu \mathrm{g} / \mathrm{lane}$ ) was electrophoresed, transferred to PVDF membranes and incubated overnight with primary antibodies against PGI (Sigma), KLF4 (Sigma), COL5A1 (Santa Cruz), fibronectin (Santa Cruz), YKL40 (Bio Scientific) respectively. Membranes were then treated with the appropriate HRP-conjugated secondary antibodies (Invitrogen). Detection was performed using the reagents provided in the ECL+Plus kit (GE healthcare).

Animal studies. The indicated glioma cells were stereotactically inoculated into the corpus striatum of right brain hemisphere $(1 \mathrm{~mm}$ anterior and $1.8 \mathrm{~mm}$ lateral to the bregma; $2.5 \mathrm{~mm}$ intraparenchymal) of 6-8 weeks old NOD/SCID mice. Immediately following inoculation, implanted animals were transferred to the intravital imaging system (Nikon) and imaged to obtain a baseline measurement. Data analysis was performed using Metamorph imaging software (Universal Imaging). For intracranial injections, when the newly formed tumor reached $0.5-0.6 \mathrm{~cm}$ in diameter, mice were placed in a stereotactic frame under anesthesia. The striatum was targeted unilaterally on the right hemisphere using a $30-\mathrm{G}$ needle (Hamilton) connected to a Hamilton $5 \mu$ l syringe. The stereotactic coordinates for the microinjections were: $+0.6 \mathrm{~mm}$ anterior and $+1 \mathrm{~mm}$ lateral to the bregma. shRNA vectors, mixed with liposome at the ratio of $1: 1$ for transfection, were injected at a rate of $1 \mu \mathrm{l} / \mathrm{min}$ over 2 minutes, twice a week, for two weeks.

Statistical analysis. Statistics were calculated by SPSS software. The results are presented as mean \pm standard error (SEM). ANOVA, Student's $t$-test analysis and Dunnett's multiple comparison tests were used to compare mean values. A $P$-value of less than 0.05 was defined as statistical significance.

\section{Results}

The degree of mesenchymal phenotype correlates with the quantity of the CD133+ GSCs in human gliomas. As shown in Fig1A and Table1, positive immunoreactivity and immunostaining intensity for either YKL40 or fibronectin (FN) (well-established mesenchymal proteins expressed in gliomas) were positively associated with histopathological grade, with expression being highest in GBMs. Noteworthy, tumors with aberrant expression of YKL40/FN were associated with increased CD133 index (Fig 1B and Table 2). The association rate 

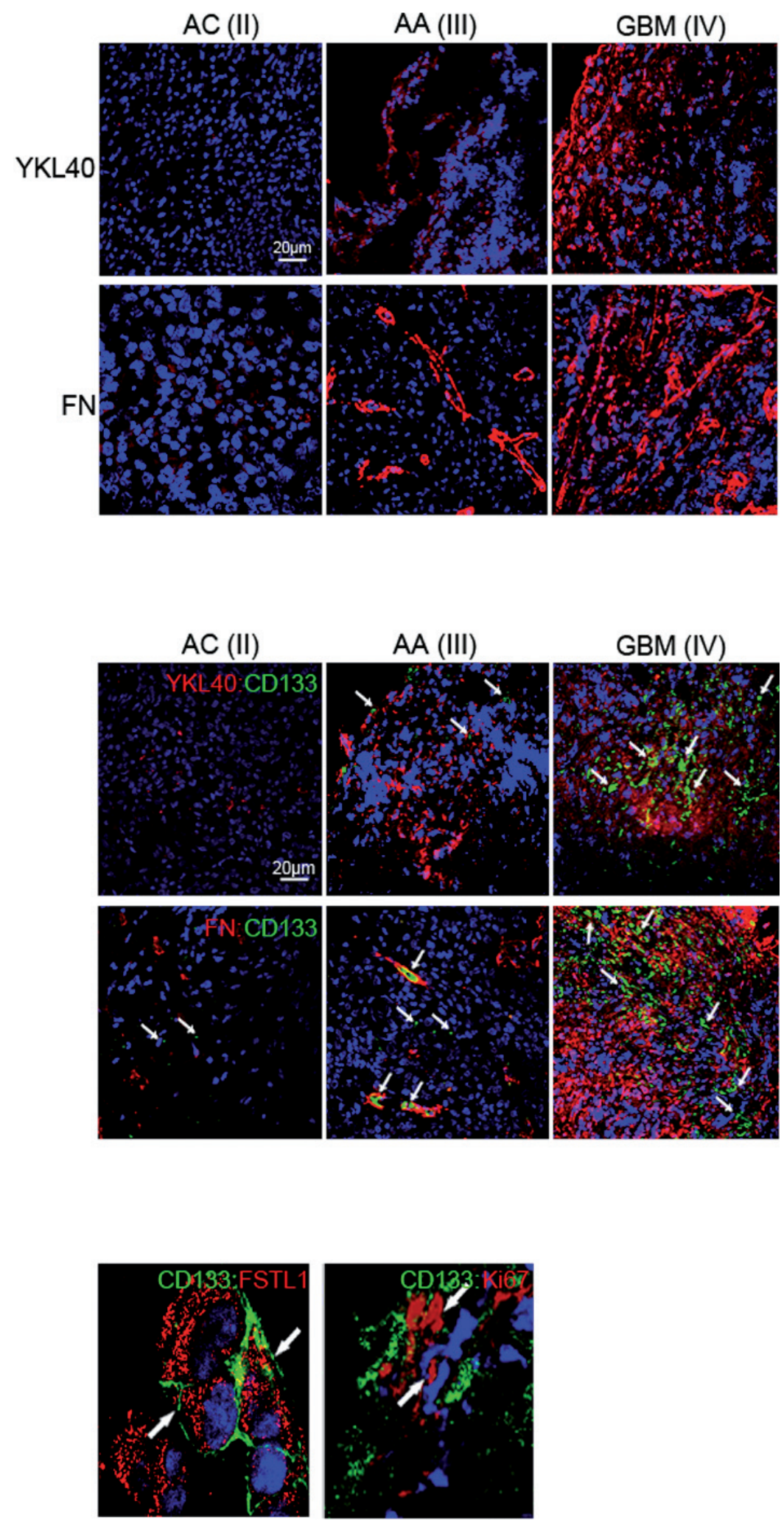

Figure 1. The degree of mesenchymal phenotype in gliomas positively correlates with the quantity of GSCs. (A). Immunofluorescence analysis for YKL40 and fibronectin (FN) in the human glioma specimens. (B). Representative images of CD133/YKL40 and CD133/FN coimmunofluorescence in sections of primary astrocytomas (AC, II), anaplastic astrocytomas (AA, III) and glioblastomas (GBM, IV). (C). Concurrent coimmunofluorescence (CD133/FSTL1) (left) and coimmunofluorescence (CD133/Ki-67) staining (right) of primary glioblastoma. Bars: $20 \mu \mathrm{m}$. 
Table 1. Correlation of YKL40 and FN expression with histological grades of gliomas.

\begin{tabular}{cccccccccc}
\hline$\square$ & $\square$ & \multicolumn{1}{c}{ YKL40 } & \multicolumn{1}{c}{ FN } \\
\hline Histological grade & number of cases & 0 & 1 & 2 & 3 & 0 & 1 & 2 & 3 \\
II & 22 & 11 & 5 & 6 & 0 & 12 & 4 & 6 & 0 \\
III & 18 & 2 & 7 & 7 & 2 & 3 & 8 & 7 & 0 \\
IV & 27 & 2 & 1 & 11 & 13 & 2 & 6 & 9 & 10 \\
R & $\square$ & & 0.937 & & & 0.965 & \\
$p$ value & $\square$ & & $<0.05$ & & & $<0.05$ & \\
\hline
\end{tabular}

Table 2. Correlation of CD133 expression with the degree of mesenchymal phenotypes in gliomas.

\begin{tabular}{|c|c|c|c|c|c|c|c|c|}
\hline \multirow{2}{*}{$\frac{\otimes}{\mathrm{CD} 133}$} & \multicolumn{4}{|c|}{ YKL40 } & \multicolumn{4}{|c|}{ FN } \\
\hline & 0 & 1 & 2 & 3 & 0 & 1 & 2 & 3 \\
\hline 0 & 16 & 4 & 1 & 0 & 15 & 6 & 0 & 0 \\
\hline 1 & 5 & 3 & 10 & 1 & 3 & 7 & 2 & 2 \\
\hline 2 & 1 & 1 & 9 & 5 & 2 & 3 & 9 & 6 \\
\hline 3 & 0 & 0 & 2 & 9 & 0 & 0 & 2 & 8 \\
\hline $\mathrm{R}$ & \multicolumn{4}{|c|}{0.886} & \multicolumn{4}{|c|}{0.893} \\
\hline $\mathrm{p}$ value & \multicolumn{4}{|c|}{$<0.05$} & \multicolumn{4}{|c|}{$<0.05$} \\
\hline
\end{tabular}

was significantly higher in high-grade gliomas (grade III and IV) versus lower-grade ones (grade II). Among those HGGs with high or moderate levels of YKL40/FN staining, 31 of 39 had a CD133 staining $\geq 2+$ intensity. However, in the lowergrade gliomas with similar immunostaining of YKL40/FN, only 2 of 8 had a CD133 staining $\geq 2+$ intensity.

We sought to determine if the CD133+ cells in gliomas are cancer cells or entrapped normal neural stem cells. Follistatin-like1 (FSTL1) has been identified as a diagnostic hallmark of primary GBMs [21]. 66.8\% $\pm 9.7 \%$ of the CD133+ cells co-expressed FSTL1, confirming that they are GBM cells. Indeed, CD133/Ki-67 double immunostaining showed that $29.1 \% \pm 11.6 \%$ of $\mathrm{CD} 133+$ cells appear to possess aberrant proliferative capacity, suggesting further that they are cancer cells (Fig 1C).

The mesenchymal environment in malignant gliomas promotes the self-renewal capacity of GSCs. We next compared the stemness properties of GSCs derived from different subtypes of gliomas. Glioma cells were isolated from three grade II astrocytomas without mesenchymal phenotype (AC13), four GBMs without mesenchymal phenotype (GBM1-4),
A

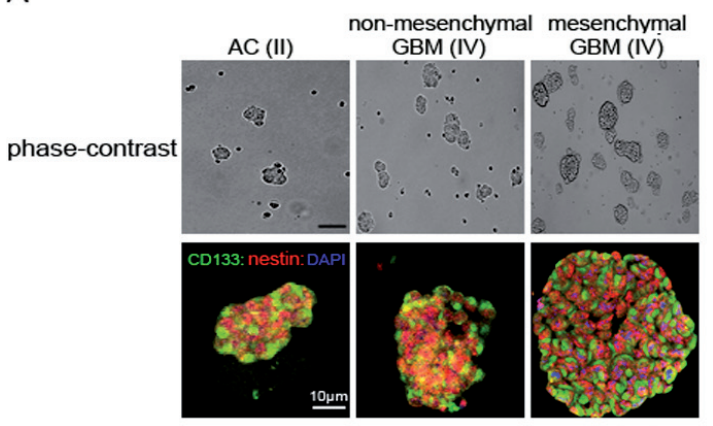

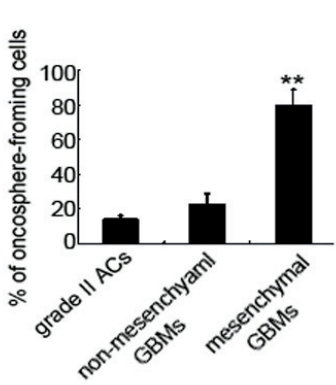

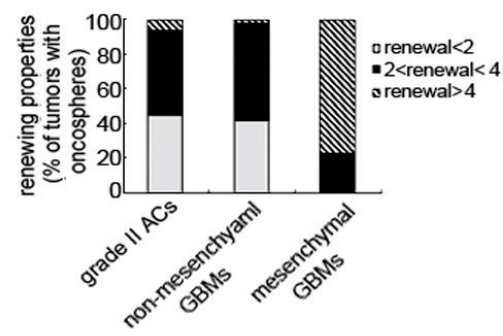

D

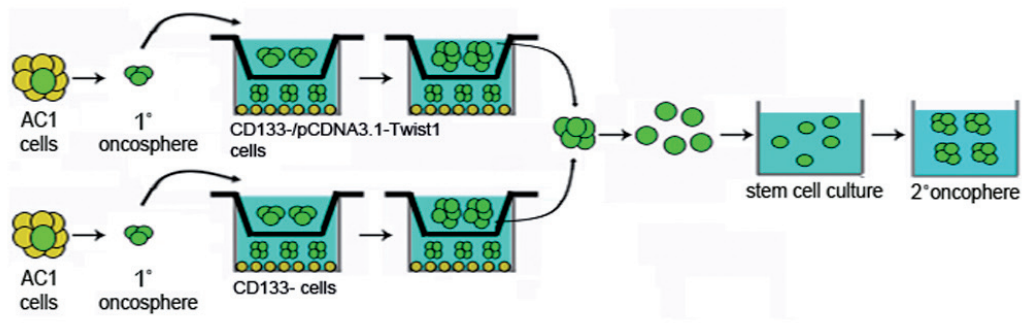

E

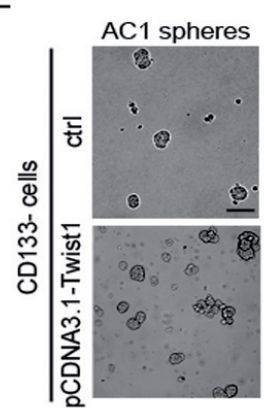

$\mathrm{F}$

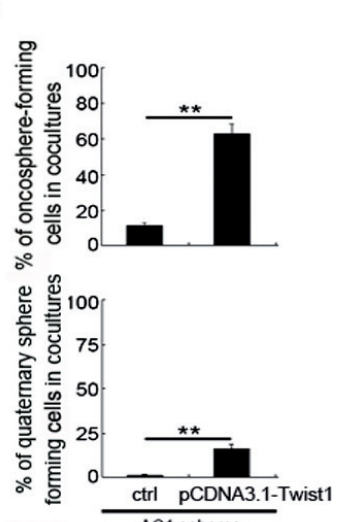

Figure 2. The aberrant mesenchymal phenotype contributes to the higher self-renewal capacity of GSCs. (A). Representative images and coimmunofluorescence (CD133/nestin) of oncospheres generated from AC1, GBM4 and GBM6. Dissociated cells from the indicated oncospheres were incubated in the absence of growth factors for 14 days, the percentage of oncosphere-forming cells (B) and the ability of cells to generate novel spheres over successive passages (C) were determined. (D). Cartoon depicting the experimental approach adopted to determine the effects of mesenchymal phenotypes on the self-renewal potential of GSCs. After AC1 spheres were transwell-cultured with $\mathrm{AC1}{ }^{\mathrm{CD} 133-\mathrm{pCDNA3} .1-\mathrm{Twist}}$ or control cells respectively, representative images are shown in (E) and the self-renewal capacity (the percentage of oncosphere-forming cells and the percentage of quaternary-forming tumor spheres) (F) was evaluated. ${ }^{* *}, p<0.05$, versus the corresponding controls cells. Bars: $10 \mu \mathrm{m}$. 
A

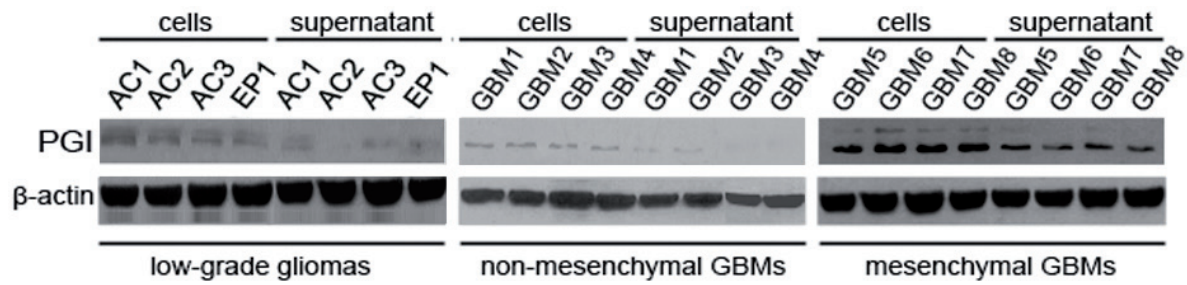

B
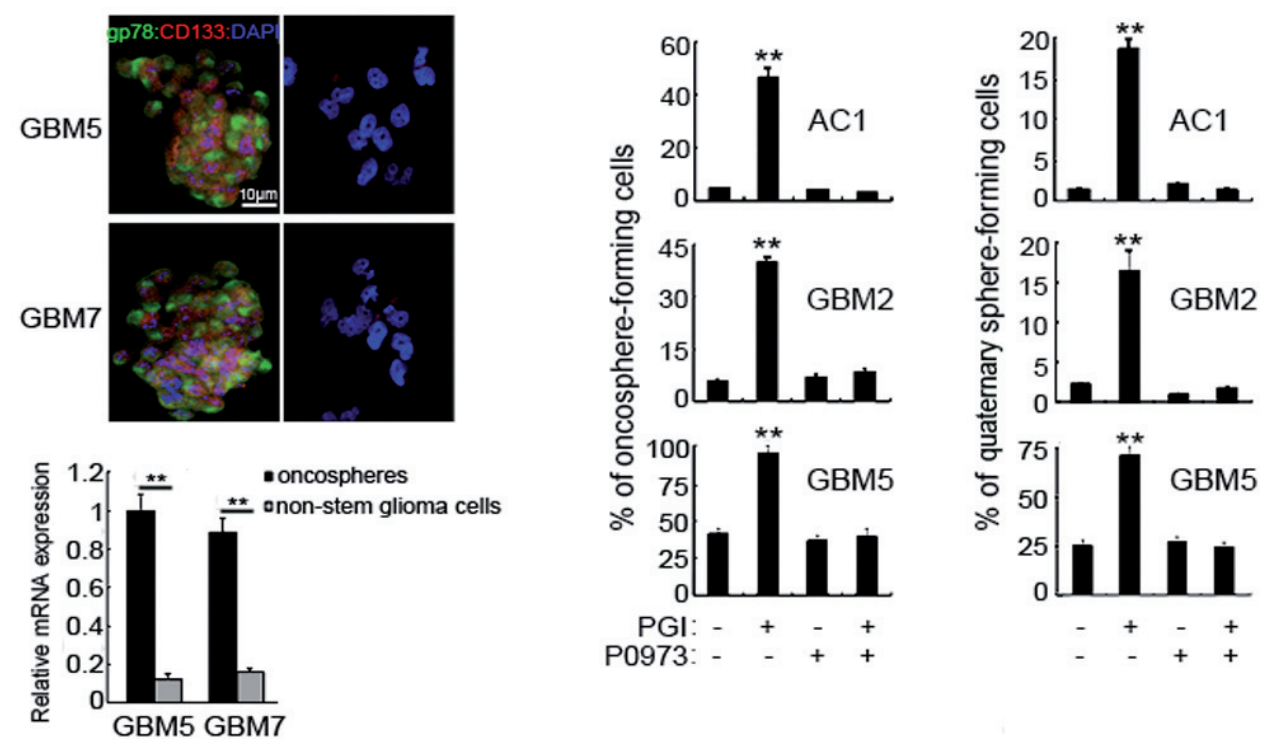

D

E
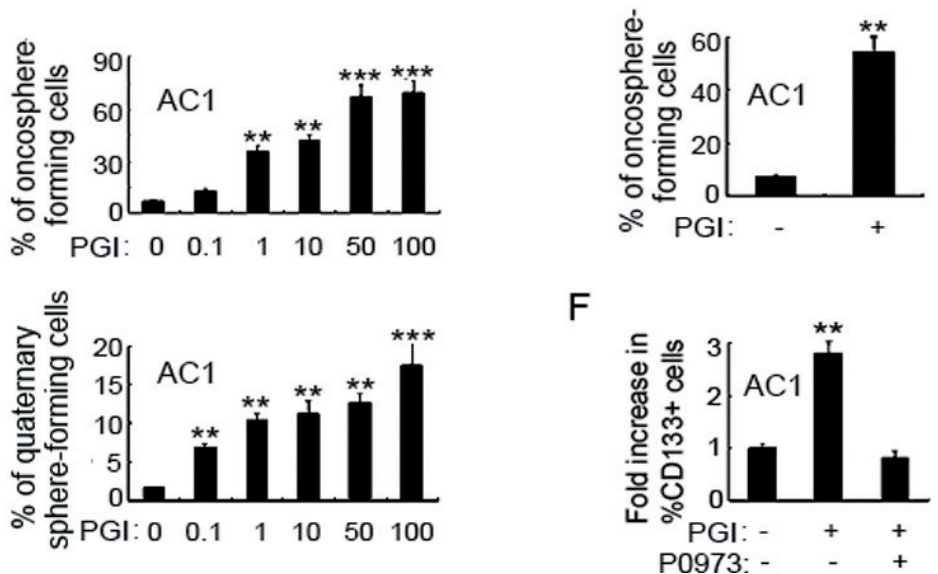

Figure 3. PGI plays a key role in mediating the interaction between mesenchymal glioma cells and GSCs. (A). PGI levels were determined by immunoblotting analysis of cell lysates and supernatant from the indicated glioma samples. (B). Representative images of CD133/gp78 coimmunofluorescence (upper panel) and CD133, gp78 mRNA levels (lower panel) in GSCs and the non-stem glioma cells. (C). In the absence of growth factors, cells from the indicated oncospheres were incubated with $50 \mathrm{ng} / \mathrm{ml} \mathrm{PGI}$ and/or $200 \mu \mathrm{g} / \mathrm{ml}$ P0973 (gp78 inhibitor) for 7 days, and the self-renewal capacity was determined as previously. (D). Cells from AC1 oncospheres were incubated with the indicated concentrations of PGI for 14 days, the self-renewal capacity was determined as previously. (E). Cells from AC1 were incubated for 14 days with PGI at a very low cell density $(0.2$ cell/ $\mu \mathrm{l})$ and the number of newly formed oncospheres was counted. (F). After cells from AC1 oncospheres were incubated with PGI and/or P0973 for 14 days, the percentage of CD133+ cells was determined by flow cytometry. ${ }^{* *}, p<0.05,{ }^{* *}, p<0.005$ versus the corresponding controls cells. Bars: $10 \mu \mathrm{m}$. 
and four mesenchymal GBMs (GBM5-8), under conditions that promote stem cell growth. Within 14 days, all individual cells produced nonadherent, multicellular oncospheres which express CD133 and nestin (Fig 2A). The more mesenchymal phenotype expressed, the quicker the cells grew and the more tumor spheres formed (Fig 2B). Moreover, oncospheres from gliomas without mesenchymal phenotypes showed limited expansion and cannot be maintained beyond passage $2(<2$ passages), whereas all mesenchymal GBMs yielded sphere cells with extended passages ( $>4$ passages) (Fig $2 \mathrm{C}$ ).

Mesenchymal differentiation contributes to enrichment of CSCs in malignant epithelial tumors. We isolated the CD133cells from two grade II astrocytomas without mesenchymal phenotypes (AC1 and AC2) and transfected them with pcDNA3.1-Twist1 (Fig S2A). The CD133- subpopulations undergoing mesenchymal change displayed no enhancement in either oncosphere-forming ability (Fig S2B) or expression of GSC markers (Fig S2C), thereby precluding the possibility that the enhanced GSC self-renewal in mesenchymal gliomas is a direct consequence of mesenchymal differentiation.

To figure out whether the differential stem-like properties is attributed to the GSCs themselves or the mesenchymal phenotype, we transferred $\mathrm{AC} 1$ oncospheres to the base of culture wells while the upper transwell compartment was seeded with the AC1 ${ }^{\mathrm{CD} 133-/ \mathrm{pcDNA3} \text {.1-Twist1 }}$ or control cells (Fig 2D). This transwell system allows the exchange of diffusible factors, but not cells, between chambers. AC1 oncospheres that were cocultured with the $\mathrm{AC1} 1^{\mathrm{CD} 133-/ \mathrm{pcDNA3} \text {.1-Twist }}$ cells formed up to 4.2 times as many oncopsheres as those grown in the presence of control cells. Moreover, these sphere cells were significantly more likely to generate quaternary tumor spheres as compared with those from control cocultures (Fig 2E), suggesting that mesenchymal condition is critical for maintaining the selfrenewal capacity of GSCs.

PGI secreted by mesenchymal glioma cells promotes GSCs self-renewal. To perform a comparative analysis of the proteins differentially expressed in the active fraction of mesenchymal glioma cells, the $\mathrm{AC1}{ }^{\mathrm{CD} 133-\mathrm{pCDNA3} .1-\mathrm{Tw} \text { ist } 1}$ and control cells were incubated in serum-free media for 3 days, after which relative protein abundance in culture supernatants was determined using label-free proteomic software and Mascot 2.2. When comparing the Twist1-overexpressing group with the control group, 36 proteins showed difference of at least 1.5fold. Of these, phosphoglucose isomerase (PGI) was found to have a more than four-fold difference between the two groups (Table S1). Our study further showed that PGI secretion in the supernatant of mesenchymal GBMs was significantly higher as compared to that of lower-grade gliomas without mesenchymal phenotype and non-mesenchymal GBMs. A similar result was observed in the whole lysed cells (Fig 3A). In all cases of normal brain tissue adjacent to the tumor, there was only negligible PGI expression (data not shown). The effects of PGI are mediated via its specific receptor, gp78 [22]. GSCs expressed elevated levels of gp78 in comparison to the nonstem glioma cells, consistent with the mRNA expression data
(Fig 3B). Although we detected PGI expression in GSCs, PGI mRNA levels (Fig S2A), as well as secreted PGI levels (Fig S2B) were remarkably higher in the non-stem glioma cells than the matched GSCs. These data suggest that paracrine signaling between the non-stem glioma cells and GSCs may predominate in the mesenchymal gliomas.

We next assessed the effect of PGI on GSCs self-renewal properties. Patient-derived oncospheres from a low-grade glioma without mesenchymal phenotype (AC1), a GBM without mesenchymal phenotype (GBM2) and a mesenchymal GBM (GBM5) were dissociated into single cells and treated with PGI or left untreated for 14 days. Treatment with PGI not only enhanced the number of oncospheres, but also increased the sphere formation efficiency with quaternary oncospheres (Fig 3C). PGI did not affect BrdU incorporation of the treated oncospheres (Fig S3). The effect of PGI was blocked when the gp78 blocking peptide, P0973, was added concomitantly with PGI (Fig 3C). In addition, there was a dose-dependent effect of PGI on the number of oncospheres with extended self-renewal capacities (Fig 3D), and the effect of PGI on self-renewal was observed even when cells were plated at very low density (Fig 3E). In agreement with the suggested effects of PGI signaling, PGI also increased the size of the CD133+ GSCs pool, which could be largely abolished by pre-treating with P0973 (Fig 3F).

PGI induces KLF4 expression in GSCs. In order to identify which PGI responses mediate GSCs self-renewal, AC1 and AC2 oncospheres were treated with PGI, gp78 inhibitor, or a combination of both for $3 \mathrm{hr}$, after which a transcriptomic analysis was performed. Among the 9 common gene responses to PGI between AC1 and AC2 sphere cells (Fig 4A; Table S2), zinc finger Kruppel-like transcription factor 4 (KLF4) stood out as for its role in cancer formation and stem cell regulation [23-25]. We firstly determined whether induction of KLF4 by PGI is a common phenomenon that takes place in most human gliomas. After the CD133- cells derived from 8 human gliomas were treated with PGI for 3h, KLF4 expression levels remained unchanged in all cases due to the absence of gp78 in the non-stem glioma cells (Fig 4B). On the contrary, PGI was able to induce KLF4 expression in the patient-derived oncospheres (Fig 4C). These effects were dependent on gp78 activity since KLF4 induction by PGI was blocked by the presence of P0973 (Fig 4D).

To study the transcriptional regulation of KLF4 by PGI, we used a luciferase reporter construct containing the $-1200 /+32$ promoter region of human KLF4 gene (Fig 4E). PGI and P0973 were able to transactivate and suppress the KLF4 reporter constructs respectively, indicating that PGI regulates KLF4 at the transcriptional level. Further, we were able to map the PGIresponsive element to the $-520 /-50$ promoter region, since the $-50 /+32$ region did not respond to PGI and the $-520 /-50$ promoter region was sufficient to be regulated by PGI and P0973 (Fig 4F). This region contains three consensus SP1-binding elements (SPE) (Fig 4E). We co-transfected oncospheres with various KLF4 promoter reporters and increasing amounts of SP1 
A

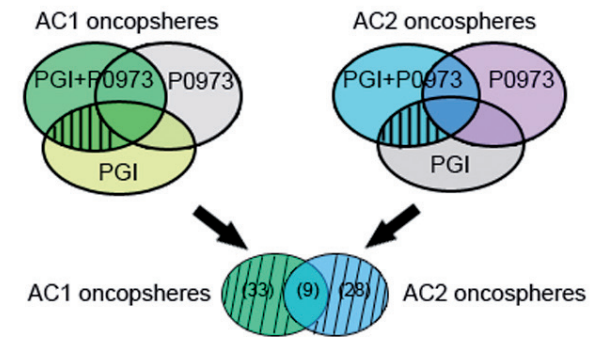

B

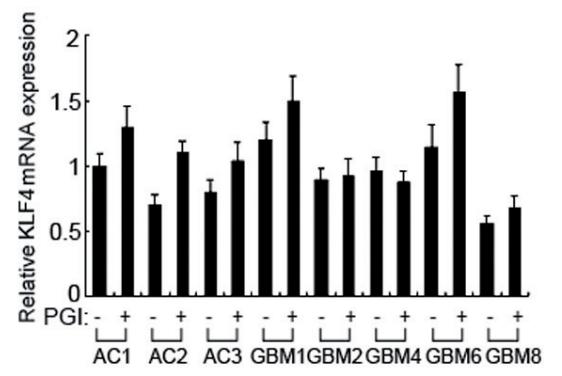

C

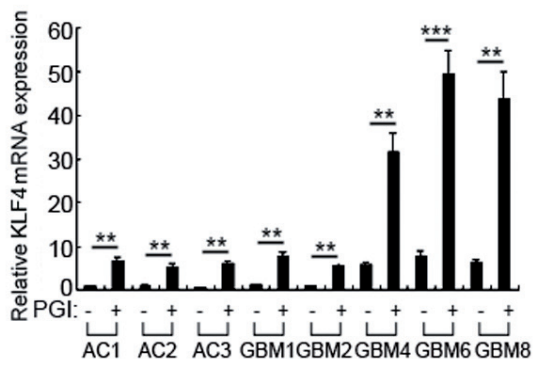

D

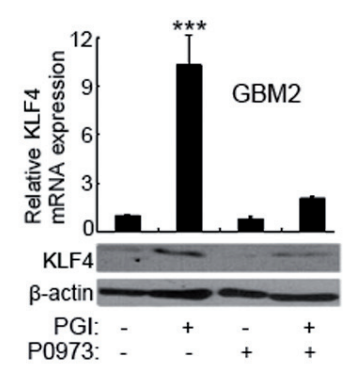

G

$\mathrm{H}$

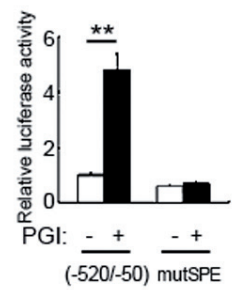

E

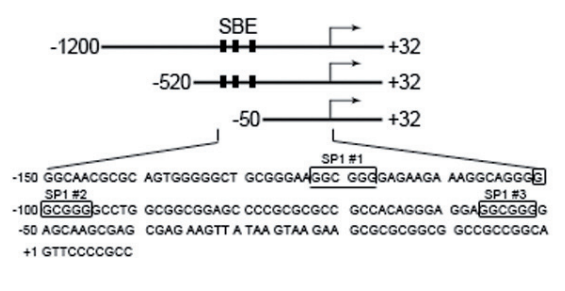

$\mathrm{F}$

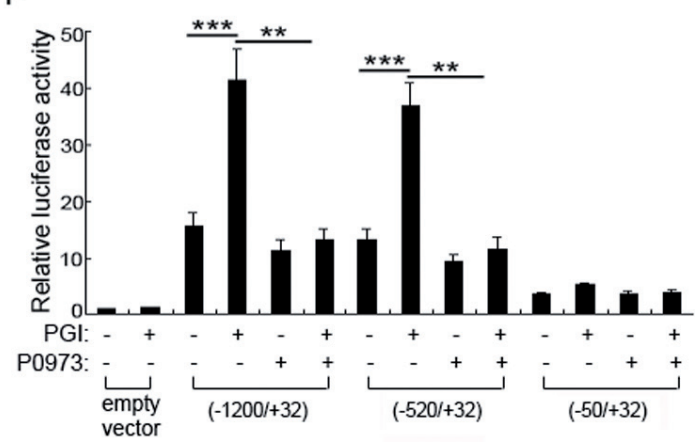

Figure 4. PGI regulates KLF4 production by GSCs. (A). Venn diagram representing data obtained from the microarray analysis of gene expression profiles of $\mathrm{AC} 1$ and $\mathrm{AC} 2$ sphere cells treated with $50 \mathrm{ng} / \mathrm{ml}$ PGI and $/$ or $200 \mu \mathrm{g} / \mathrm{ml} \mathrm{P0973} \mathrm{for} 3 \mathrm{hr}$. The non-stem glioma cells (B) and oncospheres (C) from the indicated human glioma samples were treated with 50ng/ml PGI or left untreated for $3 \mathrm{hr}$, and the levels of KLF4 expression were determined by qPCR. (D). GBM2 sphere cells were incubated with PGI and/or P0973, and KLF4 expression levels were determined by qPCR and western blotting. (E). Scheme of LIF luciferase reporter constructs. (F). GBM4 oncospheres were transfected with the indicated constructs and treated with PGI and/or P0973 for $36 \mathrm{hr}$, after which luciferase analysis was performed. (G). AC2 oncospheres were transfected with the -520/-50 mutated SP1-binding element (mutSPE) or -520/-50 KLF4 luciferase reporter constructs. Cells were then treated with PGI for $36 \mathrm{hr}$, and luciferase activity was analyzed. $(\mathrm{H})$. After AC2 oncospheres were treated with 50ng/ml PGI and siSP1, KLF4 expression was determined by luciferase analysis. ${ }^{* *}, p<0.05,{ }^{* * *}, p<0.005$ versus the corresponding controls cells.

expression plasmid. The results showed that overexpression of SP1 alone increased the activity of the -1200bp and -520bp KLF4 promoters in a dose-dependent manner. The -50bp KLF4 promoter, which does not contain the SP1 sites, was unaffected by SP1 overexpression (Fig S4). We also mutated the SPE (mutSPE, from GGCGGG to GTTTTG) and observed that the response to PGI was blunted (Fig 4G), suggesting that an activated SP1 binds to the proximal SPE in the KLF4 promoter to induce transcription. In line with this, knockdown of SP1 abolished the KLF4 response to PGI in oncopsheres (Fig 4H).

KLF4 mediates the induction of GSCs self-renewal by PGI. To further validate the effects of the PGI-KLF4 pathway on GSC self-renewal, oncospheres were dissociated into single cells and treated with lenti-KLF4, PGI, and/or siKLF4 as indicated. We observed that sphere cells treated with PGI or/and transfected with lenti-KLF4 exhibited increased number of sphere-forming cells for over four passages, whereas untreated cells yielded onco- spheres without enhanced self-renewal capacity. The PGI effect was dependent on the induction of KLF4 (Fig 5A and 5B).

Finally, we tested the potential clinical significance of these findings using in vivo expanded primary tissue from a patient with primary mesenchymal GBM (GBM6). One week after implantation, the tumor-bearing mice were randomized for treatment. The detailed experimental setup is depicted in Fig 5C. All control animals bore large, life-limiting tumors and died within 2 month after implantation. In stark contrast, for the treatment group, tumors quickly regressed and long-term survival was significantly better compared with the control group (Fig 5D and 5E). Intriguingly, phenotyping of these tumors by immunofluorescence staining revealed a virtually complete elimination of the CD133+GSCs as compared with the control tumors. Thus, interruption of the IL6-KLF4 pathway virtually decreased the tumorigenic potential of GSCs (Fig 5F). 
A
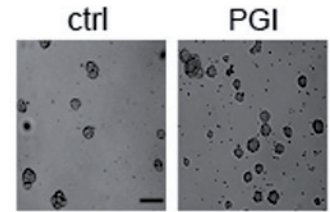

lenti-KLF4 PGI+siKLF4

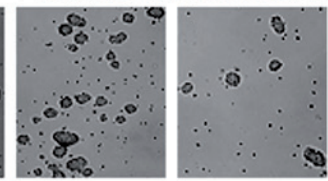

B

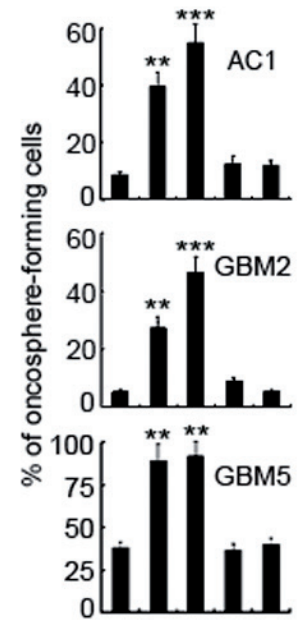

PGI: - + - - +

lenti-KLF4: - -++

SiKLF4: - - + +
C
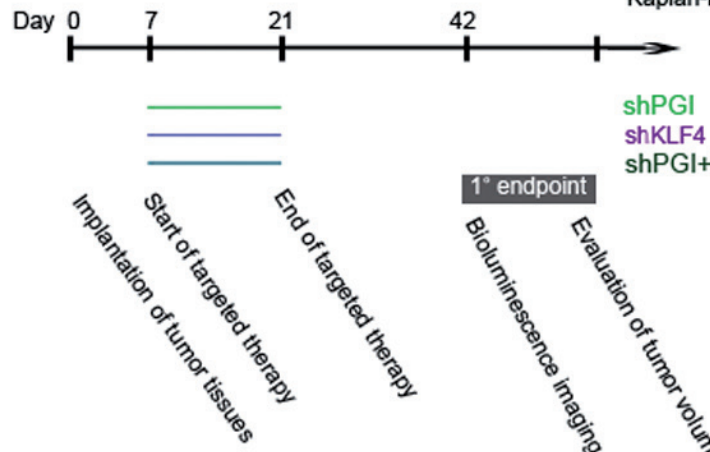

shKLF4

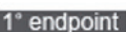

shPGI+KLF4
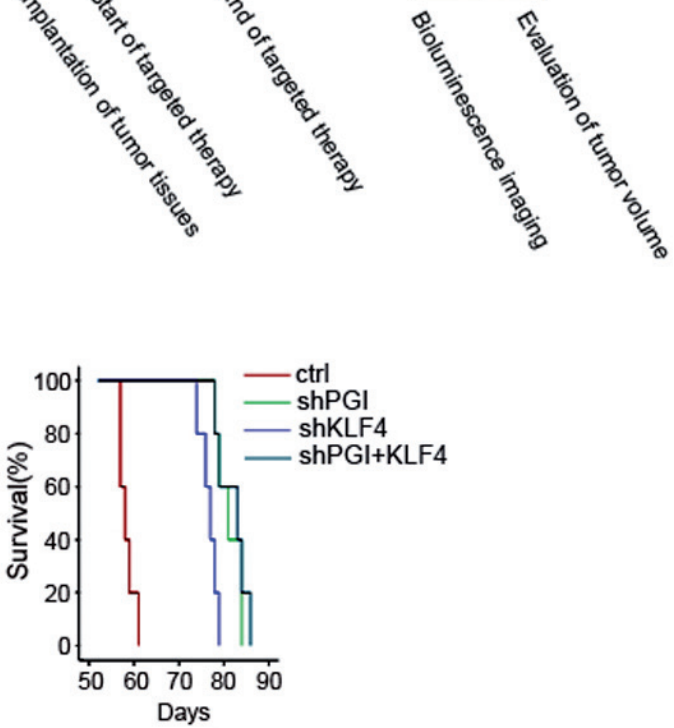

E

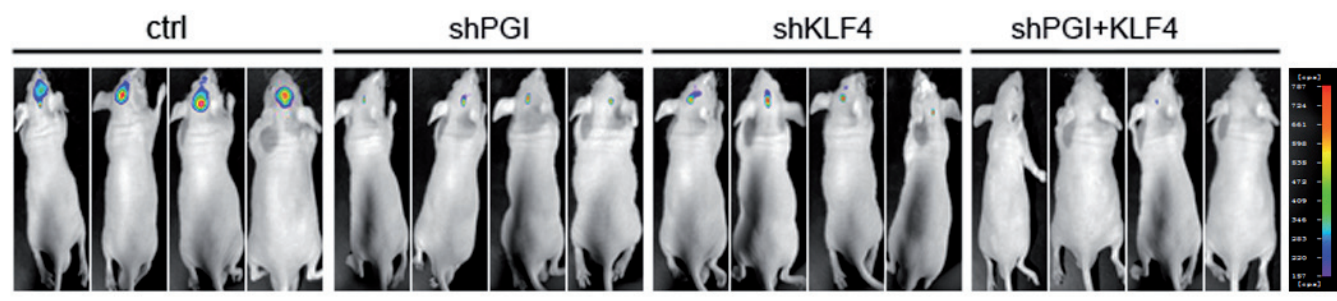

$\mathrm{F}$

ctrl

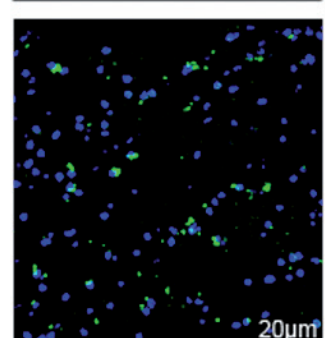

shPGI

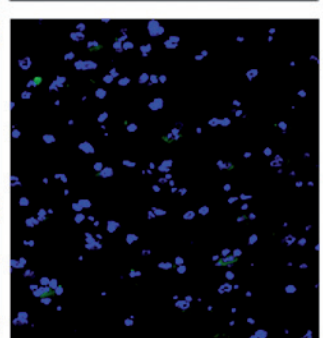

shKLF4

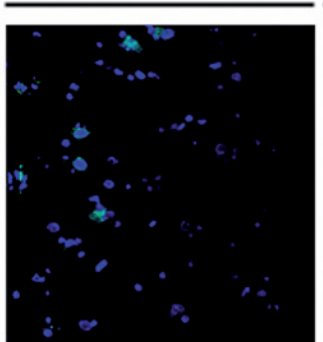

shPGI+KLF4

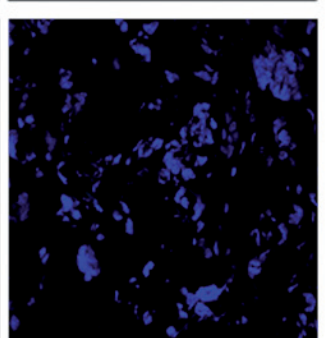

Figure 5. KLF4 mediates the effects of PGI on the stemness of GSCs. After AC1, GBM2, or GBM5 sphere cells were treated with 50ng/ml PGI, and/or transfected with lenti-KLF4 and siKLF4, representative images of GBM2 oncospheres were shown in (A), the self-renewal capacity (B) was determined. (E) Depiction of the experimental setup. After GBM6 cells were orthotopically transplanted into the brains of immunocompromised mice, shPGI or/and shKLF4 were intracranial injected for a prolonged period of 2 weeks. (D) Animal survival was evaluated using a log-rank analysis from a Kaplan-Meier survival curve. (E) Tumorigenicity was evaluated by bioluminescence imaging on day 42. (F) Immunofluorescence staining on in vivo treated tumors of $\mathrm{CD} 133$ was performed. ${ }^{* *}, p<0.05,{ }^{* *}, p<0.005$ versus the corresponding controls cells. Bars: $20 \mu \mathrm{m}$. 


\section{Discussion}

In this study, we observed that aberrant mesenchymal phenotype is associated with significant enrichment of GSCs and higher self-renewal efficiency. Although emerging evidence has indicated the involvement of mesenchymal transition in CSC development $[7,8]$, mesenchymal transformation in the non-stem glioma cells failed to directly trigger reversion to a GSC-like phenotype. Then a question was raised: what is the major factor accounting for the expanded the GSC pool in mesenchymal gliomas? GSCs are a sub-population of glioma cells that possess characteristics associated with neural stem cells (NSCs) [26, 27]. Neural stem cell activity is maintained in niches. Analogously, niches that maintain GSCs also exist [28]. The ability of niche to determine the functional spectrum of NSCs activities suggests that niche microenvironments also beget GSCs functions [29-30]. Here, we demonstrated that mesenchymal glioma cells generate a specific microenvironment that promotes the self-renewal of GSCs. Recruitment of mesenchymal niche environments is an important hallmark of high-grade gliomas [3]. Indeed, our findings well explain why primary high-grade gliomas are highly aggressive with a rapid fatal progression for the patients.

An understanding of the molecular mechanisms involved in the action of mesenchymal glioma cells on GSC stemness is crucial for design of efficient therapeutic strategies. We showed that the interaction between GSCs and mesenchymal glioma cells is mediated by a paracrine cytokine loop in which PGI plays a pivotal role. This loop requires the simultaneous presence of both cell types but does not require cell-cell contact as shown by transwell and conditioned medium experiments. PGI is tightly linked to tumor generation and poor disease outcome in many cancer types [31-34]. Our data identified a mechanism implicated in the PGI oncogenic response in human gliomas. PGI, which is secreted by mesenchymal glioma cells, regulates the self-renewal capacity of GSCs. If this paradigm proves more broadly applicable, then mesenchymal glioma cells act as a critical factor in the GSCs niche.

We have also demonstrated that PGI promotes the self-renewal capacity of GSCs through induction of KLF4. KLF4 is well known to be one of the self-renewal genes, such as Oct4 and Nanog, and to play pivotal roles in maintaining stemness of embryonic stem cells [23]. KLF4 also plays crucial roles in maintenance of NSCs, and KLF4 deficiency causes impaired neurogenesis in adult mouse brain $[23,25]$. Our report is the first, to our knowledge, to show the significance of the PGIKLF4 pathway for the maintenance of GSCs. Interruption of the PGI-KLF4 pathway can be translated into an decreased oncogenic capacity of GSCs. Thus, KLF4 is an essential factor for maintenance of GSCs as well as NSCs and embryonic stem cells, supporting the concept that malignant GSCs and normal neural stem cells are closely associated with each other in their biological properties.
Supplementary information is available in the online version of the paper.

\section{References}

[1] PHILLIPS HS, KHARBANDA S, CHEN R, FORREST WF, Soriano RH et al. Molecular subclasses of high-grade glioma predict prognosis, delineate a pattern of disease progression, and resemble stages in neurogenesis. Cancer Cell 2006; 9: 157-173. http://dx.doi.org/10.1016/j.ccr.2006.02.019

[2] TSO CL, SHINTAKU P, CHEN J, LIU Q, LIU J et al. Primary glioblastomas express mesenchymal stem-like properties. Mol Cancer Res 2006; 4: 607-619. http://dx.doi.org/10.1158/15417786.MCR-06-0005

[3] CARRO MS, LIM WK, ALVAREZ MJ, BOLLO RJ, ZHAO $\mathrm{X}$ et al. The transcriptional network for mesenchymal transformation of brain tumours. Nature 2010; 463: 318-325. http://dx.doi.org/10.1038/nature08712

[4] LEE J, KOTLIAROVA S, KOTLIAROV Y, LI A, SU Q et al. Tumor stem cells derived from glioblastomas cultured in bFGF and EGF more closely mirror the phenotype and genotype of primary tumors than do serum-cultured cell lines. Cancer Cell 2006; 9: 391-403. http://dx.doi.org/10.1016/j.ccr.2006.03.030

[5] RICH JN. Cancer stem cells in radiation resistance. Cancer Res 2007; 67: 8980-8984. http://dx.doi.org/10.1158/0008-5472. CAN-07-0895

[6] STILES CD, ROWITCH DH. Glioma stem cells: a midterm exam. Neuron 2008; 58: 832-846. http://dx.doi.org/10.1016/ j.neuron.2008.05.031

[7] MANI SA, GUO W, LIAO MJ, EATON EN, AYYANAN A et al. The epithelial- mesenchymal transition generates cells with properties of stem cells. Cell 2008; 133: 704-715. http://dx.doi. org/10.1016/j.cell.2008.03.027

[8] MUERKOSTER SS, WERBING V, KOCH D, SIPOS B, AMMERPOHL $\mathrm{O}$ et al. Role of myofibroblasts in innate chemoresistance of pancreatic carcinoma-epigenetic downregulation of caspases. Int J Cancer 2008; 123: 1751-1760. http://dx.doi.org/10.1002/ijc.23703

[9] BERTOUT JA, PATEL S, SIMON MC. The impact of O2 availability on human cancer. Nature Rev Cancer 2008; 8: 967-975. http://dx.doi.org/10.1038/nrc2540

[10] HUANG Q, ZHANG QB, DONG J, WU YY, SHEN YT et al. Glioma stem cells are more aggressive in recurrent tumors with malignant progression than in the primary tumor, and both can be maintained long-term in vitro. BMC Cancer 2008; 8: 304. http://dx.doi.org/10.1186/1471-2407-8-304

[11] THIERY JP. Epithelial-mesenchymal transitions in tumour progression. Nature Rev Cancer 2002; 2: 442-454. http:// http://dx.doi.org/10.1038/nrc822

[12] PEINADO H, OLMEDA D, CANO A. Snail, Zeb and bHLH factors in tumour progression: an alliance against the epithelial phenotype? Nat Rev Cancer 2007; 7: 415-428. http://dx.doi. org/10.1038/nrc2131

[13] SCHEEL C, ONDER T, KARNOUB AE, WEINBERG RA. Adaptation versus selection: The origins of metastatic behavior. Cancer Res 2007; 67: 11476-11479. http://dx.doi. org/10.1158/0008-5472.CAN-07-1653 
[14] KELLY PN, DAKIC A, ADAMS JM, NUTT SL, STRASSER A. Tumor growth need not be driven by rare cancer stem cells. Science 2007; 317: 337. http://dx.doi.org/10.1126/ science. 1142596

[15] JORDAN CT, GUZMAN ML, NOBLE M. Cancer Stem Cells. N Engl J Med 2006; 355: 1253-1261. http://dx.doi. org/10.1056/NEJMra061808

[16] SINGH A, GRENINGER P, RHODES D, KOOPMAN L, VIOLETTE $S$ et al. A gene expression signatureassociated with „K-Ras addiction“ reveals regulators of EMT and tumor cell survival. Cancer Cell 2009; 15: 489-500. http://dx.doi. org/10.1016/j.ccr.2009.03.022

[17] STILES CD, ROWITCH DH. Glioma stem cells: a midterm exam. Neuron 2008; 58: 832- 846. http://dx.doi.org/10.1016/ j.neuron.2008.05.031

[18] LI Z, BAO S, WU Q, WANG H, EYLER C et al. Hypoxiainducible factors regulate tumorigenic capacity of glioma stem cells. Cancer Cell 2009; 15: 501-513. http://dx.doi. org/10.1016/j.ccr.2009.03.018

[19] GILBERTSON RJ, RICH JN. Making a tumour's bed: glioblastoma stem cells and the vascular niche. Nat Rev Cancer 2007; 7: 733-736. http://dx.doi.org/10.1038/nrc2246

[20] LI QQ, CHEN ZQ, CAO XX, XU JD, XU JW et al. Involvement of NF- $\kappa \mathrm{B} / \mathrm{miR}-448$ regulatory feedback loop in chemotherapy-induced epithelial- mesenchymal transition of breast cancer cells. Cell Death Differ 2011; 18: 16-25. http://dx.doi. org/10.1038/cdd.2010.103

[21] REDDY SP, BRITTO R, VINNAKOTA K, APARNA H, SREEPATHI HK et al. Novel glioblastoma markers with diagnostic and prognostic value identified through transcriptome analysis. Clin Cancer Res 2008; 14: 2978-2987. http://dx.doi. org/10.1158/1078-0432.CCR-07-4821

[22] SILLETTI S, WATANABE H, HOGAN V, NABI IR, RAZ A. Purification of B16-F1 melanoma autocrine motility factor and its receptor. Cancer Res 1991; 51: 3507-3511.

[23] TAKAHASHI K, YAMANAKA S. Induction of pluripotent stem cells from mouse embryonic and adult fibroblast cultures by defined factors. Cell 2006; 126: 663-676. http://dx.doi. org/10.1016/j.cell.2006.07.024

[24] WERNIG M, MEISSNER A, FOREMAN R, BRAMBRINK $\mathrm{T}, \mathrm{KU} \mathrm{M}$ et al. In vitro reprogramming of fibroblasts into a pluripotent ES-cell-like state. Nature 2007; 448: 318-324. http://dx.doi.org/10.1038/nature05944
[25] ZHANG P, ANDRIANAKOS R, YANG Y, LIU C, LU W. Kruppel-like factor 4 (Klf4) prevents embryonic stem (ES) cell differentiation by regulating Nanog gene expression. J Biol Chem 2010; 285: 9180-9189. http://dx.doi.org/10.1074/jbc. M109.077958

[26] SINGH SK, CLARKE ID, TERASAKI M, BONN VE, HAWKINS C Et al. Identification of a cancer stem cell in human brain tumors. Cancer Res 2003; 63: 5821-5828.

[27] GALLI R, BINDA E, ORFANELLI U, CIPELLETTI B, GRITTI A et al. Isolation and characterization of tumorigenic, stemlike neural precursors from human glioblastoma. Cancer Res 2004; 64: 7011-7021. http://dx.doi.org/10.1158/0008-5472. CAN-04-1364

[28] SNEDDON JB, WERB Z. location, location, location: the cancer stem cell niche. Cell Stem Cell 2007; 1: 607-611. http://dx.doi.org/10.1016/j.stem.2007.11.009

[29] YANG ZJ, WECHSLER-REYA RJ. Hit ,em where they live: targeting the cancer stem cell niche. Cancer Cell 2007; 11: 3-5. http://dx.doi.org/10.1016/j.ccr.2006.12.007

[30] FLYNN CM, KAUFMAN DS. Donor cell leukemia: insight into cancer stem cells and the stem cell niche. Blood 2007; 109: 2688-2692.

[31] HOELZINGER DB, DEMUTH T, BERENS ME. Autocrine factors that sustain glioma invasion and paracrine biology in the brain microenvironment. J Natl Cancer Inst 2007; 99: 1583-1593. http://dx.doi.org/10.1093/jnci/djm187

[32] TSUTSUMI S, YANAGAWA T, SHIMURA T, KUWANO $\mathrm{H}, \mathrm{RAz}$ A. Autocrine motility factor signaling enhances pancreatic cancer metastasis. Clin Cancer Res 2004; 10: 7775-7784. http://dx.doi.org/10.1158/1078-0432.CCR-04$\underline{1015}$

[33] TALUKDER AH, BAGHERI-YARMAND R, WILLIAMS RR, RAGOUSSIS J, KUMAR R et al. Antihuman epidermal growth factor receptor 2 antibody herceptin inhibits autocrine motility factor (AMF) expression and potentiates antitumor effects of AMF inhibitors. Clin Cancer Res 2002; 8: 3285-3289.

[34] DOBASHI Y, WATANABE H, SATO Y, HIRASHIMA $S$, YANAGAWA $T$ et al. Differential expression and pathological significance of autocrine motility factor/glucose-6-phosphate isomerase expression in human lung carcinomas. J Pathol 2006; 210: 431-440. http://dx.doi. org/10.1002/path.2069 
doi:10.4149/neo_2014_049

Supplementary Information

\title{
The PGI-KLF4 pathway regulates self-renewal of glioma stem cells residing in the mesenchymal niches in human gliomas
}

\author{
X. Y. ZHU ${ }^{1, *}$, L. WANG ${ }^{2, *}$, S. H. LUAN ${ }^{3}$, H. S. ZHANG ${ }^{3}$, W. T. HUANG ${ }^{4, *}$, N. H. WANG ${ }^{5,6^{*}}$
}

${ }^{1}$ Department of traditional Chinese medicine, Shanghai Cancer Hospital, Fudan University, Shanghai, P R China; ${ }^{2}$ Department of blood transfusion, Shanghai RenJi Hospital, Shanghai JiaoTong University, Shanghai, P R China; ${ }^{3}$ Department of Neurosurgery, HuaShan Hospital, Fudan University, Shanghai, PR.China; ${ }^{4}$ Department of Pathology, Shanghai Sixth People's Hospital, Shanghai Jiao Tong University, Shanghai, P R China; ${ }^{5}$ Department of Rehabilitation Medicine, Huashan Hospital, Fudan University, Shanghai 200040, China; ${ }^{6}$ Department of Sports Medicine and Rehabilitation, Medical College of Fudan University, Shanghai 200032, China; ${ }^{7}$ Department of Rehabilitation Medicine, The Yonghe Branch of Huashan Hospital, Fudan University, Shanghai Zhabei District 200436, China; ${ }^{8}$ State Key Laboratory of Medical Neurobiology, Fudan University, Shanghai 200032, China

*Correspondence: huangwt1786@163.com,wnh2005@126.com

${ }^{*}$ Contributed equally to this work

Microarray expression analysis. RNA was harvested from the indicated cells. Three independent experiments were performed. Five micrograms of extracted total RNA was used to generate biotinylated complementary RNA (cRNA) following the standard Affymetrix GeneChip protocol. Gene expression analyses used Affymetrix U133 plus 2.0 human oligonucleotide microarrays containing over 47,000 transcripts and variants, including 38,500 well characterized human genes. Hybridizations, washes, and detection were done as recommended by the supplier. CEL files were imported into the ArrayAssist package (Stratagene) and preprocessed using the RMA (robust multiarray analysis) algorithm with the default parameters. Genes were filtered according to the following criterion: AbsFC with respect to their respective control experiments $\geq 2$. Genes complying with these criteria were then used for later study.

Protein quantitation and identification. The supernatant samples from the indicated cells were in-gel digested enzymatically and analyzed by LC-MS/MS. The database search was performed using both the X!Tandem and SEQUEST algorithms. Quantification was first performed using Mascot 2.2. Using the Mascot quantification method, protein quantification was only performed on proteins identified by two or more peptides with scores above the identity threshold. Protein differential expression was also assessed at the peptide level. All peptides were used to calculate global mean and S.D. of peptide ratios (47-1/D3). The differentially expressed peptides were used to infer differentially expressed proteins. 
A.

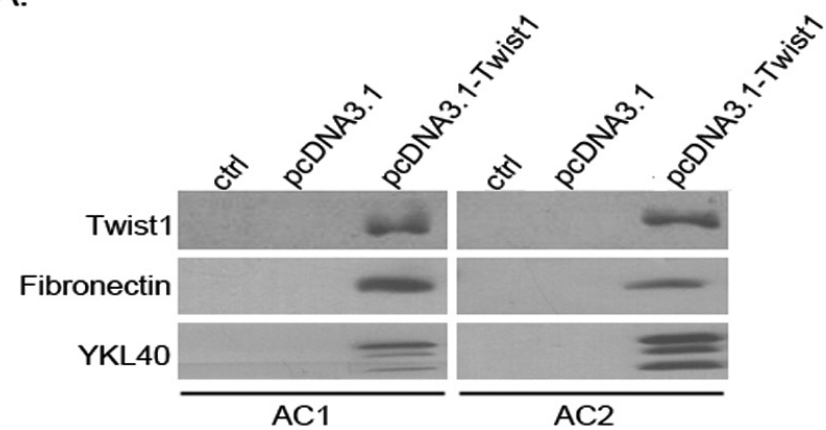

B.

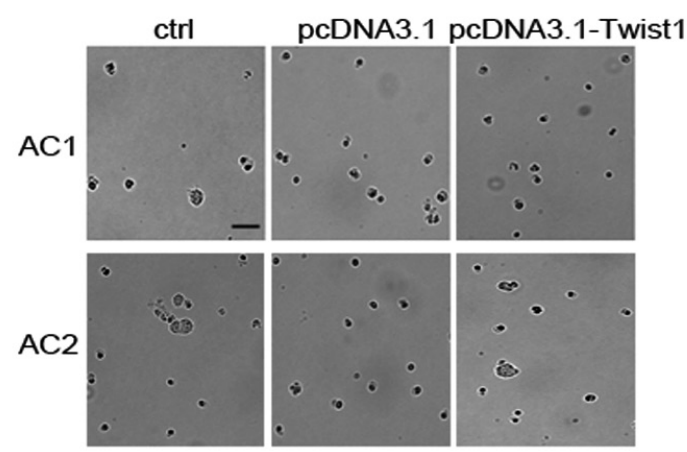

C.

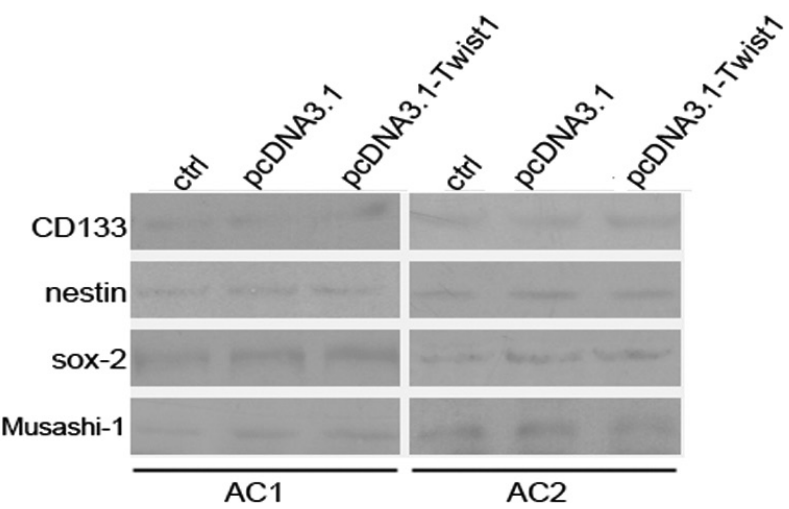

A.

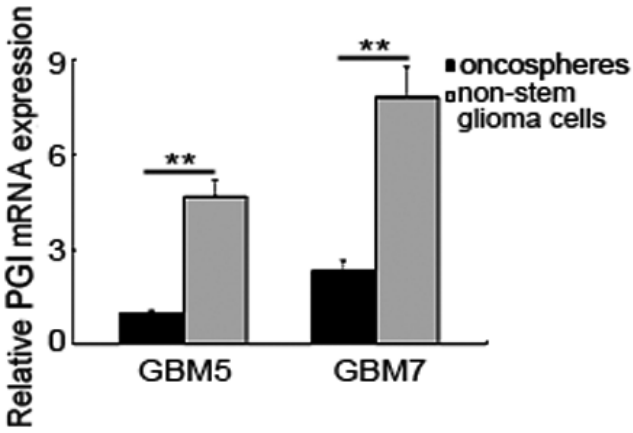

$B$.

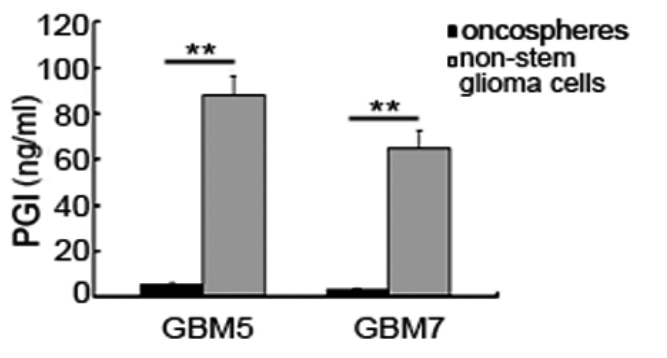

Figure S2. The non-stem glioma cells express elevated levels of PGI in comparison to GSCs. PGI mRNA levels and secreted PGI protein levels in the non-stem glioma cells and GSCs were evaluated by qPCR (A) and ELISA (B), respectively.

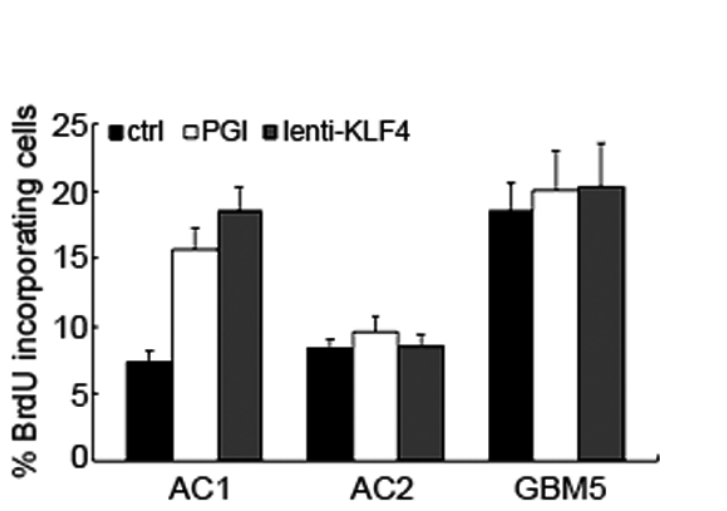

Figure S3. PGI and KLF4 exert no effects on the proliferative activity of GSCs. After oncosphere cells derived from AC1, AC2 and GBM5 samples were treated with PGI or transfected with lenti-KLF4, the percentage of BrdU incorporating cells were determined by flow cytometry. 

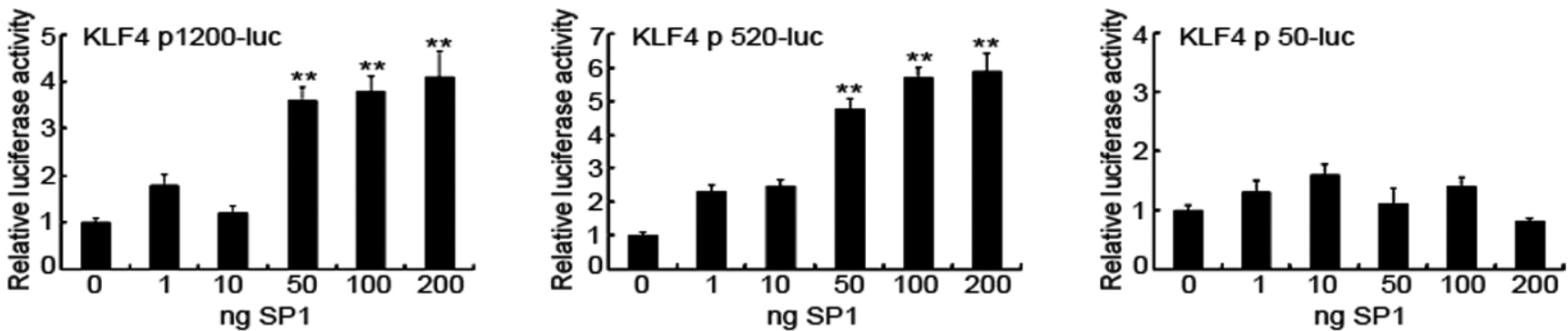

Figure S4. SP1-mediated increases in KLF4 promoter activity require sequences between -520 and $-50 \mathrm{bp}$. AC2 oncosphere cells were cotransfected with the 1,200-, 520-, or 50-bp KLF4 promoter reporter plasmid and increasing amounts of CMV-SP1 plasmid (0-200ng) for $48 \mathrm{~h}$, after which the relative changes in luciferase expression were determined. ${ }^{* *}, p<0.05$, versus the corresponding controls cells.

Table.S1 The differently expressed proteins identified based on two or more peptides in AC1CD133- cell supernatants after treatment with pcDNA3.1-Twist1.

INDEX ACCESSION PROTEIN NAME

AVERAGE

Ras GTPase-activating-like protein PROBABILITY UNIQUE PEPTIDE (pcDNA3.1-Twist1:control)

Fatty acid synthase

P60174 Triosephosphate isomerase

P60842 Eukaryotic initiation factor 4A-II

Histone $\mathrm{H} 4$

P62937

Peptidyl-prolyl cis-trans isomerase A

Ubiquitin

P62988
P68104

Putative elongation factor 1-alpha-like 3

Q05639

$\mathrm{O} 43707$

Elongation factor 1-alpha 2

Alpha-actinin-4

$\mathrm{P} 00338$

L-lactate dehydrogenase A chain

P04908

Histone H2A.J

$\mathrm{P} 05783$

Keratin, type I cytoskeletal 18

P05787

Keratin, type II cytoskeletal 8

$\mathrm{P} 06733$

Alpha-enolase

P07437

Tubulin beta- $2 \mathrm{~B}$ chain

P07900

Heat shock protein HSP 90-alpha

P11142

Heat shock cognate $71 \mathrm{kDa}$ protein

P11413

Glucose-6-phosphate 1-dehydrogenase

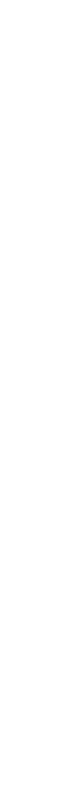

Pyruvate kinase isozymes M1/M2

P21333

Filamin-A

P60709

Actin, cytoplasmic 2

P63104

14-3-3 protein zeta/delta

P68363

Tubulin alpha-1C chain

Q06830 Peroxiredoxin-1

$\mathrm{O} 60218$

Aldo-keto reductase family 1 member B10

P04792

Heat shock protein beta-1

P05161

Interferon-induced $17 \mathrm{kDa}$ protein

P05388

$60 \mathrm{~S}$ acidic ribosomal protein $\mathrm{P} 0$-like

P06748

Nucleophosmin

P09467

Fructose-1,6-bisphosphatase 1

P09651

Heterogeneous nuclear ribonucleoprotein A1-like protein

Nucleolin

P19338

Ubiquitin-like modifier-activating enzyme 1

P22626

Heterogeneous nuclear ribonucleoproteins A2/B1

\begin{tabular}{|c|c|}
\hline 59 & 4,16 \\
\hline 2 & 4,09 \\
\hline 8 & 3,92 \\
\hline 12 & 3,78 \\
\hline 31 & 3,72 \\
\hline 6 & 3,66 \\
\hline 8 & 3,59 \\
\hline 8 & 3,56 \\
\hline 3 & 3,37 \\
\hline 5 & 2,89 \\
\hline 8 & 2,75 \\
\hline 5 & 2,49 \\
\hline 3 & 2,16 \\
\hline 2 & 2,01 \\
\hline 6 & 1,96 \\
\hline 3 & 1,92 \\
\hline 6 & 1,83 \\
\hline 4 & 1,81 \\
\hline 14 & 1,69 \\
\hline 6 & 1,63 \\
\hline 2 & 1,59 \\
\hline 6 & 1,59 \\
\hline 26 & 1,52 \\
\hline 16 & 0,63 \\
\hline 5 & 0,58 \\
\hline 7 & 0,58 \\
\hline 5 & 0,52 \\
\hline 7 & 0,47 \\
\hline 17 & 0,43 \\
\hline 18 & 0,41 \\
\hline 21 & 0,39 \\
\hline 7 & 0,37 \\
\hline 14 & 0,33 \\
\hline 4 & 0,28 \\
\hline 2 & 0,28 \\
\hline 2 & 0,26 \\
\hline
\end{tabular}




\begin{tabular}{|c|c|c|}
\hline \multirow[b]{2}{*}{ Symbol } & \multicolumn{2}{|l|}{ U87MG specific gene responses } \\
\hline & Description & Gene ontology \\
\hline TPPP & Tubulin polymerization promoting protein & $\uparrow \uparrow$ \\
\hline pdela & phosphodiesterase 1A, calmodulin-dependent & 个signaling \\
\hline C13orf15 & Chromosome 13 open reading frame 15 & $\uparrow$ \\
\hline EME1 & essential meiotic endonuclease 1 homolog 1 (S. pombe) & 个stress response \\
\hline NCAM1 & Neural cell adhesion molecule 1 & 个signaling \\
\hline LOC148413 & hypothetical LOC148413 & $\uparrow$ \\
\hline GRLF1 & Glucocorticoid receptor DNA binding factor 1 & 个signaling \\
\hline RPLP2 & ribosomal protein, large, $\mathrm{P} 2$ & $\uparrow$ protein metabolism \\
\hline COX5B & Cytochrome c oxidase subunit $\mathrm{Vb}$ & 个signaling \\
\hline BCAT1 & branched chain amino-acid transaminase 1 , cytosolic & 个other metabolic processes \\
\hline FAR2 & Fatty acyl CoA reductase 2 & 个other metabolic processes \\
\hline FABP5 & fatty acid binding protein 5 (psoriasis-associated) & 个other metabolic processes \\
\hline PDE1A & phosphodiesterase 1A, calmodulin-dependent & 个signaling \\
\hline AKAP12 & A kinase (PRKA) anchor protein 12 & 个signaling \\
\hline KCTD4 & potassium channel tetramerisation domain containing 4 & $\uparrow$ transport \\
\hline ITCH & itchy E3 ubiquitin protein ligase homolog (mouse) & 个other biological processes \\
\hline TMCO6 & transmembrane and coiled-coil domains 6 & 个other membranes \\
\hline MPL & myeloproliferative leukemia virus oncogene & 个signaling \\
\hline DNAJC21 & DnaJ (Hsp40) homolog, subfamily C, member 21 & 个transcription \\
\hline PTGER4 & prostaglandin E receptor 4 (subtype EP4) & 个signaling \\
\hline PRPS2 & phosphoribosyl pyrophosphate synthetase 2 & $\downarrow$ other metabolic processes \\
\hline RPL38 & ribosomal protein L38 & $\downarrow$ other biological processes \\
\hline EIF5B & eukaryotic translation initiation factor $5 \mathrm{~B}$ & $\downarrow$ protein metabolism \\
\hline PDGFA & platelet-derived growth factor alpha polypeptide & $\downarrow$ protein metabolism \\
\hline RPL5 & ribosomal protein L5 /// small nucleolar RNA, H/ACA box 66 & $\downarrow$ protein metabolism \\
\hline PPM1A & Protein phosphatase, $\mathrm{Mg} 2+/ \mathrm{Mn} 2+$ dependent, $1 \mathrm{~A}$ & $\downarrow$ protein metabolism \\
\hline SERPINB9 & serpin peptidase inhibitor, clade B (ovalbumin), member 9 & $\downarrow$ death \\
\hline HYLS1 & hydrolethalus syndrome 1 & $\downarrow$ other metabolic processes \\
\hline NUCKS1 & Nuclear casein kinase and cyclin-dependent kinase substrate 1 & $\downarrow_{\text {transcription }}$ \\
\hline ARG2 & arginase, type II & $\downarrow$ other biological processes \\
\hline RPAIN & RPA interacting protein & $\downarrow$ other biological processes \\
\hline \multirow[t]{2}{*}{ PNN } & pinin, desmosome associated protein & $\downarrow$ cell adhesion \\
\hline & U87MG and U373MG common gene responses & \\
\hline Symbol & Description & Gene ontology \\
\hline FBXW12 & F-box and WD repeat domain containing 12 & $\uparrow$ \\
\hline PLIN2 & Perilipin 2 & $\uparrow$ \\
\hline LRCH3 & $\begin{array}{l}\text { leucine-rich repeats and calponin homology }(\mathrm{CH}) \text { domain containing } \\
3\end{array}$ & $\uparrow$ extracellular matrix \\
\hline KLF4 & Kruppel-like transcription factor 4 & $\uparrow$ transcription \\
\hline TUG1 & taurine upregulated 1 (non-protein coding) & 个developmental processes \\
\hline RPS27 & ribosomal protein S27 & $\downarrow$ protein metabolism \\
\hline TAF15 & $\begin{array}{l}\text { TAF15 RNA polymerase II, TATA box binding protein (TBP)-associat- } \\
\text { ed factor, } 68 \mathrm{kDa}\end{array}$ & $\downarrow$ other biological processes \\
\hline DLGAP4 & discs, large (Drosophila) homolog-associated protein 4 & $\downarrow$ signaling \\
\hline FAM161B & Family with sequence similarity 161 , member B & $\downarrow$ \\
\hline
\end{tabular}




\begin{tabular}{|c|c|c|}
\hline \multirow[b]{2}{*}{ Symbol } & \multicolumn{2}{|l|}{ U373MG specific gene responses } \\
\hline & Description & Gene ontology \\
\hline LYRM7 & Lyrm7 homolog (mouse) & $\uparrow$ \\
\hline KISS1R & KISS1 receptor & $\uparrow$ cell cycle and proliferation \\
\hline RSPH10B2 & radial spoke head 10 homolog B2 (Chlamydomonas) & $\uparrow$ \\
\hline VRK2 & vaccinia related kinase 2 & $\uparrow$ protein metabolism \\
\hline ZDHHC23 & zinc finger, DHHC-type containing 23 & 个other biological processes \\
\hline TLL2 & tolloid-like 2 & $\uparrow$ other biological processes \\
\hline WIPF3 & WAS/WASL interacting protein family, member 3 & 个other biological processes \\
\hline LOC100288944 & similar to hCG1989907 & $\uparrow$ \\
\hline LACTB2 & lactamase, beta 2 & $\uparrow$ \\
\hline CUL3 & cullin 3 & $\uparrow$ cell organization and biogenesis \\
\hline OSTF1 & osteoclast stimulating factor 1 & $\uparrow$ transcription \\
\hline APLP2 & Amyloid beta (A4) precursor-like protein 2 & $\uparrow$ cell organization and biogenesis \\
\hline TNFAIP8L1 & tumor necrosis factor, alpha-induced protein 8-like 1 & $\uparrow$ \\
\hline GPR160 & G protein-coupled receptor 160 & $\uparrow$ signaling \\
\hline SEC22B & $\begin{array}{l}\text { SEC22 vesicle trafficking protein homolog B (S. cerevisiae) (gene/ } \\
\text { pseudogene) }\end{array}$ & $\uparrow$ transport \\
\hline MAEL & maelstrom homolog (Drosophila) & $\downarrow_{\text {stress response }}$ \\
\hline HRASLS & HRAS-like suppressor & $\downarrow_{\text {other biological processes }}$ \\
\hline PIGK & phosphatidylinositol glycan anchor biosynthesis, class $\mathrm{K}$ & $\downarrow$ protein metabolism \\
\hline ETNK1 & ethanolamine kinase 1 & $\downarrow_{\text {signaling }}$ \\
\hline SPCS3 & signal peptidase complex subunit 3 homolog (S. cerevisiae) & $\downarrow_{\text {signaling }}$ \\
\hline IFI6 & interferon, alpha-inducible protein 6 & $\downarrow$ \\
\hline UBE4B & Ubiquitination factor E4B (UFD2 homolog, yeast) & $\downarrow$ protein metabolism \\
\hline NUP88 & Nucleoporin $88 \mathrm{kDa}$ & $\downarrow$ transport \\
\hline UGCG & UDP-glucose ceramide glucosyltransferase & $\downarrow$ other metabolic processes \\
\hline LOC100292408 & hypothetical protein LOC100292408 & $\downarrow$ \\
\hline PSIP1 & PC4 and SFRS1 interacting protein 1 & $\downarrow$ RNA metabolism \\
\hline UBE2B & $\begin{array}{l}\text { similar to hCG1980975 /// ubiquitin-conjugating enzyme E2B (RAD6 } \\
\text { homolog) }\end{array}$ & $\downarrow_{\text {RNA metabolism }}$ \\
\hline POPDC3 & popeye domain containing 3 & $\downarrow$ \\
\hline
\end{tabular}

Arrows indicate whether IL6 induced or repressed gene expression. 